\title{
Guest Editorial: Nondualistic Experiences of Light in Near-Death Experiences and in The Tibetan Book of the Dead
}

\author{
René Jorgensen \\ University of Copenhagen
}

ABSTRACT: This editorial brings together two forms of human understanding of disembodied consciousness: the light in the near-death experience (NDE), and the Clear Light in the Tibetan Book of the Dead. I begin by telling the story of my own NDE. Then I compare my experience with the Tibetan Book of the Dead, to find points where the two are similar. To show that my NDE contained features in common with others, I also compare my experience with those found in the near-death literature. Specifically, I suggest that some NDEs provide a basis for the understanding of a nondualistic perception of the Clear Light. I also explore a broader and more unified understanding of enlightenment, based on the concept of the Clear Light. I argue that the NDEr could be on the right side of the dividing line in natural liberation, explaining how the experience of light as reported by NDErs could represent insight into spiritual liberation. Finally, I close by comparing the message from NDEs and the Tibetan Book of the Dead, and pose questions for future research in the field of near-death studies.

KEY WORDS: near-death experience; The Tibetan Book of the Dead; light; Clear Light; enlightenment; liberation.

In March of 2000, I had an experience that I would later describe as a near-death experience (NDE). I was not near to physical death but in

René Jorgensen is Danish national who lives in Montreal, Canada. Six years ago he had a near-death experience and has since been investigating its meaning. Currently he is finishing his undergraduate studies in philosophy and religion. Reprint requests should be addressed to René Jorgensen, 5193 rue Garnier, Montreal, Quebec, H2J 3T3, Canada; e-mail: renejorgensen@sympatico.ca. 
a situation where I was overwhelmed by fear and spiritual insight. On a trip to India I had a mystical experience with a girl whom I had met on my travel. At the moment my NDE happened she was questioning me and penetrating deep within me. Her questions frightened me, and with nowhere to hide, I felt as if I were pressed against a wall. I felt like a little child who was caught lying, and with no way out I was overtaken by fear. This felt like a kind of ego death, where the lying part of me was exposed and dying.

This fear caused a split in me between the lying part of me and another part of me. I believe the confusion from this split was what made me leave my body. Suddenly, in an extremely powerful sensation, I was leaving my body to a place 10 to 15 feet in the air. From there I could look down and see my body sitting where had left it. The sensation of leaving my body could be described as if I were falling, and the pull of gravity was tearing me apart. This totally overpowering sensation was a feeling of unlimited love beyond comprehension. It felt as if $\mathrm{I}$ were being dissolved in a massive explosion of pure love.

I became infinite space of what felt like unbound awareness. This state was like a transparent light, and my awareness was no longer subjective. I felt as if my awareness had no boundaries and that I knew all that there was to know in the universe, as if I were part of everything and had knowledge of it all. I recognized this state to be my true nature, as if it were my essence. This recognition that my true nature was unlimited love was the most powerful and overwhelming revelation of my life, a most profound revelation beyond human expression.

From this realization of what $I$ experienced as the true nature of reality, I now began to see my life in review. I saw all the negative actions that I had done, causing pain and suffering to others. I saw myself being angry with my mother, hurting a girlfriend, and I experienced the pain that I had inflicted upon others. Even an incident from $5^{\text {th }}$ grade that I had long forgotten came back to me during my review. During a break in school I was teasing a smaller girl in the schoolyard. In my review I saw her standing against the wall crying while I called her names. I could not hear the words, but I felt her pain. Not only did I see the pain that I was causing to her in that moment, I also felt the full consequences that my action had on her life. I felt the pain that I had planted in her, and how this pain would turn into a scar that would stay with her all her life. I felt her being 
unhappy in her years of school, becoming less outgoing as a person later in life.

In my review, I saw everything that I was ignorant about before, and this knowledge now came to me in its full depth. The pain of becoming aware of this was indescribable. Having just experienced my true nature to be infinite love, I felt as if I had gone against myself and done these things to myself. Just as the experience of love before had felt like an explosion tearing me apart, now, too, the pain I felt was equally powerful. It felt as if I were failing, and gravity was pulling me apart in the painful realization that I had gone against love as my own true nature. This experience made me humble beyond human understanding, and I felt incredibly deep regret for my actions.

Then I was shown all the suffering in the world. I saw all the hunger, all the poor people, all the conflict and war. This sensation was too intense to bear. There was no way my heart could contain all this suffering. I knew I had to do something about all the pain in the world, and that realization made the feeling change back into the alloverpowering sensation of unlimited love again. Then I had a life preview where I saw myself living my life in love and giving compassion to others. I saw myself returning, at the end of my life, to the light, and I knew that was where I would go when I died.

After my experience, I felt as if my consciousness was expanded for many days. I had lucid dreams for many nights. When I finally returned home, I started to become confused. I felt that the reality that I had experienced was more real than the one I was in now. This made me believe that there were two realities, where before there had been only one. The feeling of equal reality of the two worlds made me confused about which was the real one. I started to wonder if I had lost my mind, and I began psychotherapy to regain my foothold in this world. I went through a full year of therapy before I had found the right balance between the two realities.

My psychotherapist called my experience a "dramatic ego death experience" in which I had been "confronted by a spiritual insight I was not prepared to understand." Through working with the theories of Carl Jung, my therapist helped me integrate my experience and regain my foothold in this world. By understanding the spiritual or paranormal elements of my experience, I regained my inner balance.

Before this experience, I had always viewed myself as an atheist. I never believed in God, and when people would raise this subject, I would always ask for "proof" of His existence. But my experience gave 
me a proof that was almost too big to handle. The transformation from believing in nothing, to having a direct experience of a transcendent state of reality, more real to me than this world, had a powerful impact on my mind. I was blown away beyond comprehension, and convinced that there was more in our universe than meets the eye.

This revelation opened me to alternative thinking. I began to study religion and philosophy, where I found many descriptions that resembled my experience. Through the practice of meditation, I could reconnect with the state of mind that I had experienced. But it was not until I came across the recent research into NDEs that I truly felt at home. The NDE was the most precise description of what had happened to me, and I was relieved to find that there were many others who had reported similar experiences.

\section{Merging with the Light}

I was stimulated to write this editorial in response to the article in this Journal entitled, "The Reimagination of Death: Dream Yoga, Near-Death, and Clear Light," by Raymond Lee (2004). In this article and other comparisons between NDEs and the Tibetan Book of the Dead, I noted a tendency to focus on the differences between the two, resulting in important similarities being overlooked.

It certainly seems true, as Lee wrote, that many NDErs seem to have a dualistic perception of the light. NDErs' reports of being in heaven and of seeing beings of light and religious figures suggest a clear separation between the experiencer and the light. However, as in my own experience, not all NDErs have a dualistic experience of the light. My reason for writing this editorial is to bring a nondualistic perspective to readers of this Journal.

In the Tibetan Book of the Dead, the Clear Light appears after death in the Luminous Bardo of Dharmata. Here the Ground Luminosity, or the true nature of mind, manifests itself as the Clear Light. This manifestation of the light happens not only to selected individuals but to ordinary people as well (Tsele Rangdröl, 2002, p. 47). W. Y. EvansWentz wrote that "At this moment, the first (glimpsing) of the Bardo of the Clear Light of Reality, which is the Infallible Mind of the DharmaKaya, is experienced by all sentient beings" (Evans-Wentz, 2004, p. 92).

The mind of Dharmakaya is the ultimate nature of mind, and it is described as the fundamental truth, in which all dualities merge into 
transcendent oneness (Lodö, 1987, p. 7). Assuming the two lights are one and the same, NDErs who merge with the Clear Light would experience transcendent oneness. And the oneness with this fundamental reality of the mind would be the basis of enlightenment or spiritual liberation. Enlightenment or liberation, in Buddhist context, means awakening to the true nature of the mind, which is seen as the fundamental truth.

Lee wrote that both Melvin Morse and Mark Fox saw merely a dualistic relationship to the light: the light was viewed only as an external object acting on the NDEr, rather than being part of the NDEr's identity (Lee, 2004, p. 231). My own NDE did not have a dualistic relationship to the light. Rather, my experience was that of a nondual awareness of the light as internally self-contained. I was one with the light, and there was no difference between perceiver and perceived, which made it an experience of nonduality. For me, one of the best interpretations of this experience came from Carl Jung, who wrote:

The union of the conscious mind or ego-personality with the unconscious personified as anima produces a new personality compounded of both. ... Not that the new personality is a third thing midway between conscious and unconscious, it is both together ... both ego and non-ego, subjective and objective, individual and collective. It is the "uniting symbol" which epitomizes the total union of opposites. (Yates, 1999, p. 78)

Furthermore, my experience of merging with the light was not unique. There are other NDEs with no division of subject and object, and other NDErs do share my experience of merging with the light. This merger with the light can be experienced, as in my case, as consciousness dissolving into space, as being pure consciousness without occupying any space. Raymond Moody wrote: "They didn't feel that, after the release, they were in any kind of 'body' at all. They felt as though they were 'pure' consciousness" (Moody, 1975, p. 42). In the Tibetan Book of the Dead we find that

There is no projectionist who projects thoughts by thinking them, then, one's own mind, completely free from conceptual projections, will become luminously clear. This intrinsic awareness, union of inner radiance and emptiness, is the Buddha-body of Reality. (Dorje, 2005, p. 45)

Sogyal Rinpoche also wrote about some NDErs merging with the light: "Others recount how they not only see the light, but enter 
directly into the light" (Sogyal, 1992, p. 324). He also gave one of the clearest accounts in describing this merger from Margot Grey's research: "I had no sense of separate identity. I was the light and one with it" (Grey, 1985, p. 46).

In my NDE I experienced something similar: I was in total union with the light as my true nature. The phenomenon that provided the "no I" experience was that my awareness seemed to be unbound and omnipresent. I was no longer myself; I was the light. Another NDEr expressed this experience as "I was the LIGHT and the LIGHT was me" (Atwater, 2000, p. 28).

Margot Grey reported that 39 percent of NDErs experienced being "enveloped in light and love" (Grey, 1985, p. 31). One experiencer explained, "I was one with pure light and love. I was one with God and at the same time one with everything." Another explained, "All was fusion" (Grey, 1985, p. 33). Another NDEr explained, "This radiation of love entered me and instantly I was part of it and it was part of me" (Grey, 1985, p. 48). Others use the words "a boundless sense of expansion," "a merging into the light," and "light enveloped me" (Grey, 1985 , p. 47).

Grey concluded, "Many people report feeling enveloped by this light" (Grey, 1985, p. 44). Raymond Moody found similar cases: "There was a gold-looking light, everywhere. Beautiful. I couldn't find a source anywhere. It was all around coming from everywhere." Another NDEr explained, "There was a sense of perfect peace and contentment; love. It was like I was part of it" (Moody, 1977, p. 24). Peter Fenwick also reported that some NDErs entered the light. He wrote, "Although some people describe entering the light and feeling themselves enfolded in it, enveloped in warmth and love, for others there is a realisation that the light marks a point of no return" (Fenwick and Fenwick, 1995, p. 58).

This experience in some NDEs seems similar to the "Supreme Union" between child and mother described in the Tibetan Book of the Dead. This union is the merger with the objective Clear Light of the transparent ultimate reality beyond subject-object duality, where one becomes "purified" (Thurman, 2001, p. 130). In the Tibetan tradition this purification happens as the gross mind, or conceptual mind, is dissolved into the true nature of mind. Thurman explained this as follows: "At enlightenment the ordinary mind expands in an experience of oneness with the infinity of beings and things, which becomes a permanent awareness" (Thurman, 2001, p. 248). 
This union happens after death when we leave the Bardo of Dying, and enter into the Bardo of Dharmata. This bardo, or state, holds the Sambhogakaya Luminosity, a light that is extremely clear, brilliant, open, and empty. In this state one feels free and blissful (Nyima Rinpoche, 2003, p. 127). The dividing line between the two bardos is the moment we cease clinging to our ego, and our innate wisdom, the Luminosity of Dharmata, appears in its purest state, which is felt as a mindless oblivion (Nyima Rinpoche, 2003, pp. 121 and 113).

This, for me, is a precise description of what happened in my NDE, crossing the line from subjective ego awareness to an open and empty mindless oblivion that felt blissful. I felt my awareness dissolving, or expanding, into infinite space of unlimited love. It was as if my subjective awareness expanded into a boundless state of pure consciousness.

This inner dissolution process that takes place in the Bardo of Dharmata sounds to me like what I experienced. The beginning of the Bardo of Dharmata starts with the seven very subtle dissolution stages. This dissolution ends in the display of the Ground Luminosity, described like a cloudless sky, as awareness and emptiness of primordial purity (Tsele Rangdröl, 2002, p. 52). This experience of pure and empty awareness was also part of my NDE. The unfolding of the Bardo of Dharmata begins with consciousness dissolving into space, and then space into luminosity. Luminosity then dissolves into union, which then dissolves into wisdom. Wisdom then dissolves into presence, which finally dissolves into purity of awareness (Nyima Rinpoche, 2003, pp. 14-15): "At this point, it is the nature of things that the person will automatically have the five superknowledges, the six recollections, and perfect recall, previously known as well as unknown, will arise within one's mind" (Tsele Rangdröl, 200l, p. 52).

The state of Nirvana, or enlightenment, holds the "highest fruit of wisdom," being a state of ultimate freedom beyond this world as the final truth (Thurman, 2001, pp. 248 and 267). Just as this state of enlightenment holds the knowledge of everything, so too does the light in the NDE hold all the answers to the universe. One NDEr said she "knew the answer to every mystery - I was not told, I just knew, the light held all the answers" (Fenwick and Fenwick, 1995, p. 74). Another said, "It seemed that all of a sudden, all knowledge - of all that had started from the very beginning, that would go on without end - that for a second I knew all the secrets of all ages, all the meaning of the universe, the stars, the moon - of everything" (Moody, 
1977, p. 10). Another said, "It was in all forms of communication, sights, sounds, thoughts. It was any- and everything. It was as if there was nothing that wasn't known. All knowledge was there, not just in one field, but everything" (Moody, 1977, p. 11).

In the NDE this is sometimes felt as a homecoming. Fenwick wrote: "not only is the experience felt as complete, but this completeness is a 'coming home'. It is as if they had always known this state" (Fenwick and Fenwick, 1995, p. 69). Moody also found that some compared death to a "homecoming," while others likened it to other psychologically positive states, such as awakening, to graduating, or escaping from jail (Moody, 1975, p. 97).

Moody further wrote: "This has been described as a moment of enlightenment in which the subject seemed to have complete knowledge" (Moody, 1977, p. 18). Fenwick reached a similar conclusion: "With the peace often comes a feeling of profound knowledge, a realisation that you have been given the answer to all the secrets of the universe" (Fenwick and Fenwick, 1995, p. 74). An NDEr reported: "Enlightenment is the wonder, and here I understood the universe" (Fenwick and Fenwick, 1995, p. 74).

Another feature that is common to both the NDE and the Tibetan Book of the Dead is the sensation of the merger with the light. Just as the NDE holds an extreme sensation, so too does the final state of liberation. In my experience, it was a powerful pull like gravity dissolving my body in an explosion of unlimited love beyond comprehension.

In the Tibetan Book of the Dead, recognizing the Clear Light at death is the supreme accomplishment of the "Great Seal." This is described as follows: "Ultimate reality as the ultimate lover, experiencing voidness as a total mental and physical union between oneself as orgasmic bliss" (Thurman, 2001, p. 125). In the Buddhist tradition, this ultimate reality is described as "being indescribable, inconceivable, and unable to be signified by any word, gesture, or concept" (Ponlop, 2006, p. 45).

This, to me, sounds very much like the NDE. My experience felt like an explosion of pure love a thousand times stronger than anything I have ever experienced in this dimension. Again, this experience of mine is not unique:

Some people consider a very intense sexual experience as love and they consider it possibly the most beautiful moment of their life - and it couldn't even begin to compare. All of these wonderful, wonderful feelings combined could not possibly compare to the feeling, the true 
love. If you can imagine what pure love would be, this would be the feeling that you'd get from this brilliant white light. (Ring, 1985, p. 58)

Another NDEr reported: "the only way I can describe it, is pure bliss and love" (Fenwick and Fenwick, 1995, p. 6). Fenwick wrote, "Often people feel that the experience is one of universal love, that the structure of the world is love" (Fenwick and Fenwick, 1995, p. 12). In Fenwick's British sample of more than 300 NDErs, 77 percent experienced peace or euphoria (Fenwick and Fenwick, 1995, p. 163). Grey found in a British sample of 38 NDErs that 47 percent experienced peace and euphoria, and 29 percent experienced joy and happiness (Grey, 1985, p. 31). The Evergreen Study of 55 NDEs found 74.5 percent included serenity with a feeling of overwhelming peace (Lindley, Bryan, and Conley, 1981), and in the Southern California Study of 50 NDEs, this number was 70 percent (Green and Friedman, 1983).

Fenwick explained further:

\begin{abstract}
About 88 per cent of those who filled in our questionnaire described feelings of calm or peace or joy during their experience ( 82 per cent mention peace and calm, about 40 per cent feelings of joy). This means that these positive feelings are far more common than the light or the tunnel, or indeed any of the other phenomena of the NDE. (Fenwick and Fenwick, 1995, p. 69)
\end{abstract}

\title{
The Dividing Line
}

The real issue in this is, of course, whether the NDE is or is not a staircase to enlightenment. We all have different reasons for our beliefs, and my belief comes from what I find to be very similar experiences in the NDE and the Tibetan Book of the Dead. Now, to take on the core issue, I offer an alternative view on the dividing line in enlightenment that is more open to the NDE. I argue only that NDErs have the possibility of reaching enlightenment, not that all NDErs are guaranteed to reach it.

From the Buddhist view, His Holiness, the Dalai Lama, wrote:

to begin with, it's not at all true that one needs to be an experienced yogi in order to experience the clear light. Everyone can have that encounter. It's quite feasible that the experiences of light that (NDErs have) described are facsimiles of clear light. (Dalai Lama, 1997, p. 208) 
In the Tibetan Book of the Dead we find that the dividing line in spiritual liberation is whether or not we are able to recognize the light. By recognizing the light we recognize the true nature of mind, the Ground Luminosity, and thereby we are liberated. In the Tibetan tradition there is no doubt that the Ground Luminosity is the true ground of liberation, and that the Clear Light is the basis of this liberation into the ultimate reality. People who fail to be liberated do so either because they fail to recognize the Clear Light, or because they are not able to remain in its continuity (Tsele Rangdröl, 2002, p. 48).

Now, the essential question arises: what does it take to recognize the light? The Buddhist tradition emphasizes purifying the mind through meditation, which is an excellent method. We also find techniques of visualization and the help of masters, together with Dream Yoga, as Lee pointed out. But could the door to liberation not also be open to NDErs?

Lee explained that generally, without nondualistic training as in Dream Yoga, the NDEr cannot become cognizant of the continuum between mind and light (Lee, 2004, p. 232). But as I quoted from the Dalai Lama above, it does not take an experienced yogi to experience the light, and therefore, the question remains: what does it mean to train in a nondualistic state of mind?

In the Bardo Guidebook, Chökyi Nyima Rinpoche wrote: "training in it means simply maintaining a continuity of wakefulness" (Nyima Rinpoche, 2003, p. 131). I agree that meditation is a very good tool for training the mind, but I do not think that meditation is the only way to bring about a continuity of wakefulness.

As humanity evolves, so, too, does the mind. As more and more people in the world experience the effects of the Age of Enlightenment, they may also experience a continuity of wakefulness. And as people learn to reflect they may also purify their minds, bringing about a natural state of nonconceptual wakefulness. When we consider that people from all cultures have been dying peacefully for ages, and that many NDErs have met the light and have gained confidence in its nature, it seems to me that the dividing line in spiritual liberation should be broader.

Sogyal wrote: "Even though the Ground Luminosity presents itself naturally to us all, most of us are totally unprepared for its sheer immensity" (Sogyal, 1992, p. 261). But I would suggest that most NDErs are not unprepared for this immensity. They rather look 
forward to it. Tsele Natsok Rangdröl explained that ordinary people do not attain liberation because they lack confidence in and familiarity with the light (Tsele Rangdröl, 2002, p. 67). But many NDErs have that confidence and familiarity. They are very positive about death: "I have no fear when my time for dying comes. I look forward to it with expectation of that wonderful joy and peace" (Fenwick and Fenwick, 1995, p. 130). Fenwick found that 82 percent of NDErs said that they had less fear of death (Fenwick and Fenwick, 1995, p. 3). Moody wrote: "In some form or another, almost every person has expressed to me the thought that he is no longer afraid of death" (Moody, 1975, p. 94).

The NDE imparts confidence about dying because of a sense of familiarity with the light. The experience often includes a sense of "coming home" with a feeling of peace and love, from which some NDErs do not want to return to this life. This corresponds with the state of Amitabha Buddha, where one is born in the land of ultimate bliss and peace. "The Sambhogakaya represents the Supreme Joy. If you can realize this extraordinary joy and wisdom, you will attain the state of Amitabha, and you will not be lost in the Bardo" (Lodö, 1987, p. 6).

The reason that people fail to reach enlightenment at death is that they are unable to recognize the Clear Light. I am not saying that experiencing the light equals liberation, since it is still possible for the experiencer to get lost in the life review or other realms. But if the Clear Light and the light of the NDE are one and the same, then recognition of the Clear Light at death should at least be easier for those who have already seen the light before in an NDE.

Chökyi Nyima Rinpoche wrote:

Someone who has realized the Ultimate truth of the natural state, totally beyond mental constructs, does not have to undergo these Bardos. The Bardo states are only experienced by people who have not recognized the Ultimate truth and actualized it (Nyima Rinpoche, 2003, p. 163)

Enlightenment at death is easier than attaining full enlightenment in life. Tsele Rinpoche wrote that it is easier to recognize our true nature, the Ground Luminosity, at death, because the mind is set free. As we leave the body, the mind is ungrounded and unfettered by the encasement of the body (Nyima Rinpoche, 2002, p. 157). Those experiencers who have realized the nature of the light in their NDEs should have a greater chance of recognizing it again when they die. Sogyal Rinpoche wrote: "Once the nature of mind has been introduced 
and you recognize it, you have a key to recognizing it again" (Sogyal Rinpoche, 1998, p. 263).

The key is to recognize our essence, which is the light. When the door to liberation opens through the light, we enter it by knowing who we are, and abiding in that state (Evans-Wentz, 2004, p. 91). Whether we learn to abide in this state through meditation, Dream Yoga, walking, washing the dishes, or an NDE, it is still the same essence. All beings possess the seed of enlightenment through the essence of the mind (Nyima Rinpoche, 2003, p. 116). So why should we not all have a chance at reaching enlightenment?

One of the greatest Tibetan masters of all time, Milarepa, said that "The Dharma-Kaya of thine own mind thou shalt see; and seeing that, thou shalt have seen the All - The Vision Infinite, the Round of Death and Birth and the State of Freedom" (Evans-Wentz, 2004, p. 82). The point of enlightenment is to see through the illusion, to attain the insight of emptiness beyond the concepts of the mind. Inseparable from emptiness is luminosity, the presence of what is real (Fremantle, 2000 , p. xvi).

The essence of this luminous light is love. It is by "the power of our devotion" we enter the door of Nirmanakaya (Nyima Rinpoche, 2003, p. 148), which can be interpreted as if it is by the power of love that we become enlightened. By remembering love, we become love, and so we become liberated into the light. By recognizing our true nature to be love, we merge with the light in a blissful sensation. Having had this experience before, many NDErs feel they know this love, and they feel confident that this is where they will go when they die.

According to the Tibetan Book of the Dead, death causes the dreamer to awaken to a reality of love and compassion. In the NDE, some people experience a homecoming in which all knowledge is revealed, and this "secret" of the universe is love:

The central message that the near-death experiencers bring back from their encounter with death is exactly the same as that of Buddha and the bardo teachings: that the essential and most important qualities in life are love and knowledge, compassion and wisdom. (Sogyal, 1992, p. 332)

In this respect, both the NDE and the Tibetan Book of the Dead seem to focus not on death, but on life, on how we live our lives.

I suggest further research on what aspects of NDEs precipitate change in the lives of the experiencers. Atwater found the number of NDErs who have been affected in a "significant" or "radical" way to be 
79 percent (Atwater, 2000, p. 211). What insight revealed in the NDE brings about this change? What force is it that impacts the NDEr in this profound way?

\section{References}

Atwater, P. M. H. (2000). The complete idiot's guide to near-death experiences. Indianapolis, IN: Alpha Books.

Dorje, G. (2005). The Tibetan book of the dead. London, England: Penguin.

Doore, G. (1990). What survives? Contemporary explorations of life after death. Los Angeles, CA: Jeremy P. Tarcher.

Evans-Wentz, W. Y. (2004). The Tibetan book of the dead. New Delhi, India: Winsome Books.

Fenwick, P., and Fenwick, E. (1995). The truth in the light: An investigation of over 300 near-death experiences. London, England: Headline.

Fremantle, F., and Trungpa, C. (2000). The Tibetan book of the dead. New Delhi, India: Shambhala.

Goswami, A. (2001). Physics of the soul: The quantum book of living, dying, reincarnation, and immortality. Charlottesville, VA: Hampton Roads Publishing.

Green, J. T., and Friedman, P. (1983). Near-death experiences in a Southern California population. Anabiosis: The Journal of Near-Death Studies, 3, 77-95.

Grey, M. (1985). Return from death: An exploration of the near-death experience. London, England: Arkana.

Lee, R. L. M. (2004). The reimagination of death: Dream yoga, near-death, and clear light. Journal of Near-Death Studies, 22, 221-234.

Lama, Dalai (1997). Sleeping, dreaming, and dying: An exploration of consciousness with the Dalai Lama. Boston, MA: Wisdom Publications.

Lindley, J. H., Bryan, S., and Conley, B. (1981). Near-death experiences in a Pacific Northwest American population: The Evergreen Study. Anabiosis: The Journal of Near-Death Studies, 1, 104-124.

Lodö, Lama (1987). Bardo teachings: The way of death and rebirth. Ithaca, NY: Snow Lion.

Moody, R. A. (1975). Life after life. Covington, GA: Mockingbird Books.

Moody, R. A. (1977). Reflections on life after life. St. Simon's Island, GA: Mockingbird Books.

Rinpoche, Chökyi Nyima (2003). The bardo guidebook. New Delhi, India: Rupa.

Rinpoche, Ponlop (2006, May). The two truths. Shambhala Sun, Vol. 14.

Rinpoche, Sogyal (1998). The Tibetan book of living and dying. London, England: Rider.

Thurman, R. A. F. (2001). The Tibetan book of the dead. New Delhi, India: Harper Collins.

Tsele, Natsok Rangdröl (2002). The mirror of mindfulness. New Delhi, India: Rupa.

Yates, J. (1999). Jung on death and immortality. Princeton, NJ: Princeton University Press. 